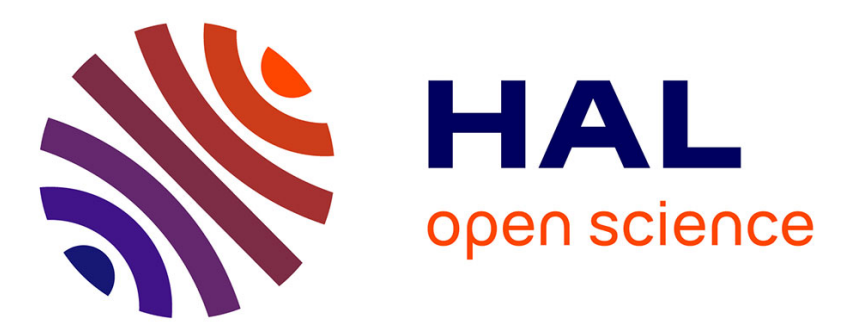

\title{
Existence of a threshold for brittle grains crushing strength: two-versus three- parameter Weibull distribution fitting
}

\author{
Ioannis Stefanou, Jean Sulem
}

\section{- To cite this version:}

Ioannis Stefanou, Jean Sulem. Existence of a threshold for brittle grains crushing strength: two-versus three- parameter Weibull distribution fitting. Granular Matter, 2015, 10.1007/s10035-015-0603-z . hal-01262954

\section{HAL Id: hal-01262954 \\ https://hal-enpc.archives-ouvertes.fr/hal-01262954}

Submitted on 27 Jan 2016

HAL is a multi-disciplinary open access archive for the deposit and dissemination of scientific research documents, whether they are published or not. The documents may come from teaching and research institutions in France or abroad, or from public or private research centers.
L'archive ouverte pluridisciplinaire HAL, est destinée au dépôt et à la diffusion de documents scientifiques de niveau recherche, publiés ou non, émanant des établissements d'enseignement et de recherche français ou étrangers, des laboratoires publics ou privés. 


\title{
Existence of a threshold for brittle grains crushing strength: two- versus three- parameter Weibull distribution fitting
}

\author{
I. Stefanou and Jean Sulem
}

Université Paris-Est, Laboratoire Navier, Ecole des Ponts ParisTech, Marne-la-Vallée, France

\begin{abstract}
:
Grain crushing plays an important role in the mechanical behavior of granular media, in chemohydro-thermo-mechanical couplings, in instabilities related to strain localization such as shear bands and compaction bands, in geophysical and geotechnical processes, in reservoir and petroleum engineering and in many other domains. The strength of brittle particles seems to be quite well described by a two-parameter Weibull distribution. Nevertheless, such a distribution predicts that failure is possible under any level of applied stress. On the contrary a threeparameter Weibull distribution contains a stress threshold under which grain failure is unlikely. Based on existing experiments on crushing of individual grains from various geomaterials and surrogate materials, and on new experiments performed on rock sugar particles, the present paper explores and compares the applicability of a two- versus a three parameter Weibull distribution. It is shown that in most of the cases the three-parameter Weibull distribution better describes the experimental results.
\end{abstract}

\section{Keywords:}

Grain crushing, Two-/Three-parameters Weibull statistics, compaction bands, softening, strain localization, geomechanics 



\section{Introduction}

The mechanical behavior of a granular material is based on the arrangement of its grains, their interaction and their strength. The complex behavior of granular materials has been studied by many researchers and the upscaling of the mechanical properties of a granular medium remains still an open research topic. Several phases may be distinguished during the deformation of a granular material. At the very early stage of loading, a granular material densifies up to a point and its macroscopic stiffness increases (Hidalgo, Grosse, Kun, Reinhardt, \& Herrmann, 2002). This is related to the progressive formation of new granular force chains. Then the material behaves linearly up to the point where the force chains start to collapse either due to grain rearrangement and/or grain crushing. Both mechanisms co-exist, in a certain way, and they are responsible for energy dissipation, which might be related to plasticity and damage.

Several works have been devoted to the study of the evolution of grain size and its relation to macroscopic measures such as deformation, energy, stress etc. For instance we refer to the works of McDowell \& Bolton (1998), Mcdowell (2002), Lade et al. (1996), Einav (2007) among others. More recently, due to important applications on geological storage and petroleum engineering the understanding of the behavior of granular material (cemented or not) under various chemo-hydrothermo-mechanical couplings became a challenging field (Brantut \& Sulem, 2012; Regenauerlieb et al., 2013; Sulem \& Famin, 2009; Sulem, Stefanou, \& Veveakis, 2011; Veveakis, Stefanou, \& Sulem, 2013; Veveakis, Sulem, \& Stefanou, 2012). For example, grain damage and crushing might be related to dissolution, creep phenomena and strain localization (Stefanou \& Sulem, 2014). Moreover, the size of the granular particles and its evolution under loading and under the aforementioned multiphysical couplings is connected with the thickness of deformation bands such as shear bands, compaction bands or shear enhanced compaction bands (e.g. Mühlhaus \& Vardoulakis 1987; Vardoulakis \& Sulem 1995; Sulem et al. 2011). These strain localization instabilities may be related to fault reactivation, seismicity, reservoir leakage and other risks. The failure probability of brittle granular particles was found to be consistent with a twoparameter Weibull distribution (Weibull, 1939a, 1939b, 1951). The Weibull distribution ansatz is justified by the extreme value theorem in statistics (Fisher-Tippett-Gnedenko theorem) and it was corroborated by experiments of individual grains crushing for different geomaterials (e.g. Nakata, Hyodo, et al. 2001; Nakata et al. 1999; Nakata, Kato, et al. 2001; McDowell \& Amon 
2000; Mcdowell 2002; Alshibli \& Cil 2012). Some tests were also performed in surrogate materials such as pasta, rice and cornflakes (McDowell \& Humphreys, 2002). Nevertheless, a two-Weibull fitting predicts that failure of grains is possible at any level of applied loading, which may not hold in general. The purpose of the present paper is to reexamine the available data found in the literature (at least the data that the authors could post-process) and investigate whether a three-parameter Weibull distribution is more appropriate or not. The present analysis is completed by fitting some additional tests on individual rock sugar crystals crushing that were conducted in the framework of this research.

In section 2 we show the main differences between a two- and a three-parameter Weibull distribution and we present the methodology that we followed for the statistical fitting. In section 3 an important amount of existing experimental data is analyzed again and fitted with a two- and a three-parameter Weibull distribution. Next, in section 4, new grain crushing experiments on rock sugar particles are detailed and the resistance of the sugar grains is statistically described. Finally, in section 5, the influence of the grain size on the parameters of the Weibull distribution is discussed. It is found that in most cases a three-parameter Weibull distribution represents better the probability of failure under given stress.

\section{Two- and three-parameter Weibull distribution}

In strength of materials and engineering practice, the probability of failure of a material is often described by the Weibull distribution. The application of this distribution is based upon the weakest link concept and on extreme value theory. In particular, Weibull distribution is a special case of the General Extreme Value (GEV) distribution. According to the extreme value theorem (Fisher-Tippett-Gnedenko theorem) the GEV distribution is the only possible limit distribution of properly normalized maxima (or minima) of a sequence of independent and identically distributed random variables. Considering that a grain is consisted of a large (theoretically infinite) number of sub-particles, whose failure is described by independent, identically distributed random variables $X_{i}$ (i stands for particle $i$ over $n$ particles with $n \rightarrow \infty$ ) and that the failure of the grain occurs when one sub-particle fails (weakest link concept), then according to the extreme value theorem the probability of failure of the grain follows the GEV distribution. If additionally, one considers that the failure distribution of the sub-particles is bounded from above 
or below (e.g. uniform distribution for $\mathrm{X}_{\mathrm{i}}$ ) then the GEV distribution degenerates to the wellknown three-parameter Weibull (3PW) distribution (for more details we refer to de Haan \& Ferreira, 2006; Rinne, 2009). The cumulative distribution function of a three-parameter Weibull function is given by:

$$
P_{f}=\left\{\begin{array}{cc}
1-\exp \left[-\left(\frac{\sigma-\sigma^{*}}{\sigma_{0}}\right)^{m}\right] & \text { for } \sigma \geq \sigma^{*} \\
0 & \text { for } \sigma<\sigma^{*}
\end{array}\right.
$$

where $m$ is the Weibull modulus, which determines the shape of the distribution, $\sigma_{0}$ a scaling parameter, which here we call characteristic stress and $\sigma^{*}$ a shift parameter, which here we call failure stress threshold. The characteristic stress and the failure stress threshold depend on the material, the shape and the size of the particles tested, at least. Often in the literature, the exponent of the distribution (called "material function" in the early paper of Weibull, 1939a) is expressed in terms of the volume and the cross-sectional area of the specimens tests (see for instance Mogi 1962). Yet, we prefer to keep here the above general mathematical form in order to avoid any a priori bias in the interpretation of the results. Section 5 is dedicated to the investigation of the dependence of the Weibull parameters on the size of the particles tested.

For $\sigma^{*}=0$ the two-parameter Weibull distribution is recovered as a special case. In a twoparameter Weibull distribution (2PW) the probability of failure (cumulative distribution function) under an applied stress $\sigma$ is expressed as follows:

$$
P_{f}=\left\{\begin{array}{cc}
1-\exp \left[-\left(\frac{\sigma}{\sigma_{0}}\right)^{m}\right] & \text { for } \sigma \geq 0 \\
0 & \text { for } \sigma<0
\end{array}\right.
$$

Single grain crush tests have shown a good correlation of the compression resistance with a two parameters Weibull distribution (Alshibli \& Cil, 2012; Mcdowell, Cil, Li, \& Alshibli, 2013; McDowell \& Humphreys, 2002; Mcdowell, 2002; Nakata, Kato, et al., 2001). Nevertheless, a potential disadvantage of the two-parameter Weibull distribution is that it predicts that failure is possible at any stress level (provided $\sigma>0$ ), which might not be realistic. In other words it might be possible for some materials to exhibit a threshold stress $\sigma^{*}$ under which failure is not possible (Figure 1). A three-parameter Weibull distribution (3PW) can express this stress threshold and provide a better correlation. In Figure 1 we present the probability density function 
for different values of $m$. Higher values of $m$ represent a material whose resistance is less dispersed.

Two ways are commonly used for fitting a two-parameter Weibull distribution. The first one is based on linear regression of the data in a log-log diagram and the second one is the Maximum Likelihood Estimation (MLE) method. MLE generally gives more accurate results. This was also corroborated by the authors for the data that they analyzed, as MLE resulted in higher P-Values. Only the results from the MLE method will be presented herein. For fitting the three-parameter Weibull distribution, an hybrid method was followed due to the well-known difficulties of the MLE method in this case. In particular, the stress threshold $\sigma^{*}$ was determined first by regression and then the $m$ and $\sigma_{0}$ were calculated by MLE (see ReliaSoft Corporation 2013). Weibull++ software was used for the analysis (ReliaSoft Corporation, 2014).
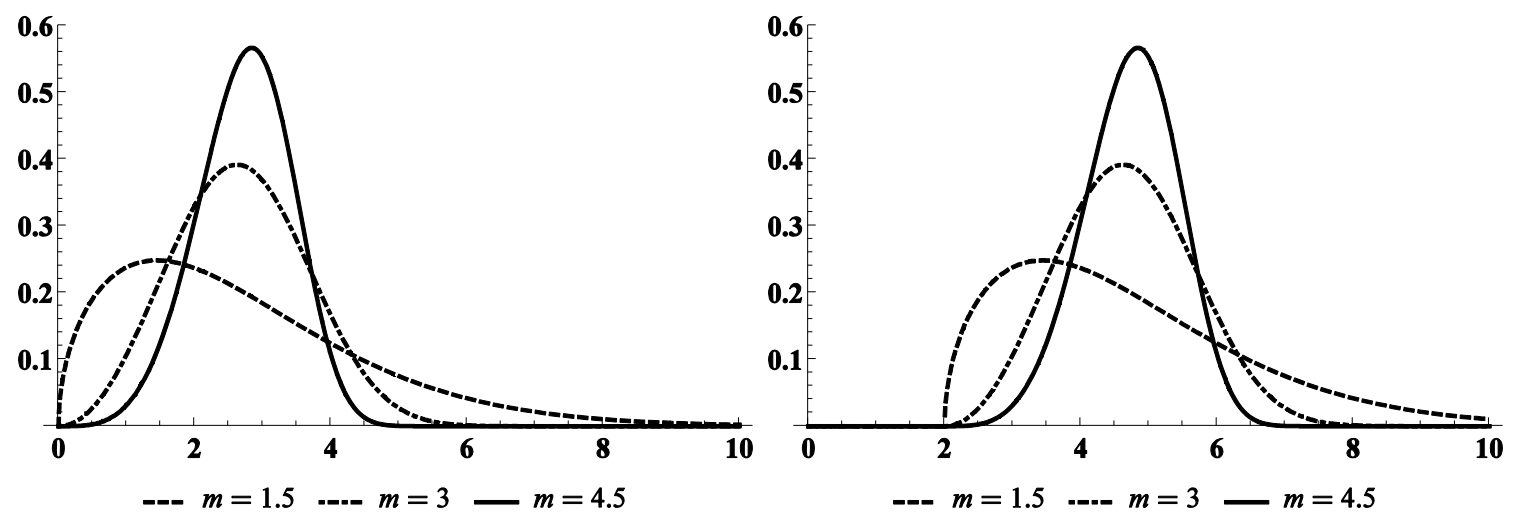

Figure 1. Left: two-parameter Weibull probability density functions for various values of $m$. Right: three-parameter Weibull probability density functions for the same values of $m$ and $\sigma^{*}=2 . \sigma_{0}$ was held constant.

The goodness of fit of the two- and three-Weibull distributions was examined in terms of the Pvalue that was calculated on the base of the Kolmogorov-Smirnov test. A small P-value suggests that it is unlikely for the data to come from the chosen distribution. The standard deviation for the calculated Weibull parameters will be also presented as an additional measure of the goodness of fit. Of course, the P-Value can be calculated on the base of additional statistical tests such as the Pearson $\chi^{2}$, Anderson-Darling, Cramer-Mises, Kuiper, Watson $\mathrm{U}_{2}$ etc.. Nevertheless, here we use only the Kolmogorov-Smirnov test as it was quite representative for the goodness of fit between 2PW and 3PW. 
The statistical analysis was based on existing data for single silica grain crush tests and on new experiments performed by the authors on rock sugar grains.

\section{Existing experimental data}

The data collected from the literature refer to the works of McDowell \& Amon (2000), Nakata et al. (2001), McDowell \& Humphreys (2002), Mcdowell (2002) and Alshibli \& Cil (Alshibli \& Cil, 2012; Mcdowell et al., 2013). Table 1 summarizes these experiments on sand grains and other surrogate materials.

Table 1. Existing experiments on single grain crushing considered in this study.

\begin{tabular}{cccc}
\hline Number & Source & Particle material & $\begin{array}{c}\text { Nominal } \\
\text { particle size } D \\
{[\mathrm{~mm}]}\end{array}$ \\
\hline 1 & & & 1 \\
2 & (McDowell \& & limestone & 2 \\
3 & Amon, 2000) & (Quiou sand) & 4 \\
4 & & 16 \\
5 & & quartz & $1.4-1.7$ \\
\hline 6 & (Nakata, Kato, et al., & (silica sand) & $1.4-1.7$ \\
7 & 2001) & Masado sand \\
\hline 8 & (quartz \& feldspar) & \\
9 & Cornflakes \\
10 & Humphreys, 2002) & Rice krispies & 0.5 \\
11 & & Pasta & 1 \\
12 & (Mcdowell, 2002) & (Leighton Buzzart silica sand) & 2 \\
\hline 13 & (Alshibli \& Cil, & Otawa sand & $0.599-0.853$ \\
14 & 2012; Mcdowell et & & \\
\hline
\end{tabular}

In Table 2 we present the Weibull modulus and the characteristic stress as they were previously published. It has to be mentioned that in all the aforementioned publications, a two-parameter Weibull distribution was followed and that the Weibull parameters were calculated using data regression. When available, we present also in the same table the coefficient of determination in order to show the quality of the regression. In Table 3 we present the $2 \mathrm{PW}$ parameters that were 
calculated in the present study following the MLE method. The standard deviation of the Weibull parameters is also given.

In Figure 2 and Figure 3 we compare the parameters found here with the ones previously published. In most of the cases the values determined previously in the literature, fall into the standard deviation margin calculated in this paper. The difference between the parameters determined herein with the ones previously published is due to: a) the different method chosen herein for the distribution fit, b) the way that the failure probability was calculated in the previous works (it was not based on the median rank method) and c) to the fact that we had access only to the plots and not to the exact numerical values of the data. Generally, it is worth mentioning that in almost all the cases, the goodness of fit with the MLE approach was superior in terms of the PValues to the one provided by regression. Therefore, one should expect that the Weibull parameters calculated by MLE fit better the experimental data. A regression fit was also performed in the frame of the present analysis but it is not presented herein.

Table 2. Weibull modulus, $m$, and characteristic stress, $\sigma_{0}$, as they were previously published $(2 P W)$.

\begin{tabular}{cccc}
\hline Number & $\begin{array}{c}\text { Weibull } \\
\text { modulus } m\end{array}$ & $\begin{array}{c}\text { Characteristic } \\
\text { stress } \sigma_{0} \\
{[\mathrm{MPa}]}\end{array}$ & $\begin{array}{c}\text { Coefficient of } \\
\text { determination }\end{array}$ \\
\hline 1 & 1.32 & 109.3 & $\mathrm{n} / \mathrm{a}$ \\
2 & 1.51 & 41.4 & $\mathrm{n} / \mathrm{a}$ \\
3 & 1.16 & 4.2 & $\mathrm{n} / \mathrm{a}$ \\
4 & 1.65 & 0.73 & $\mathrm{n} / \mathrm{a}$ \\
5 & 1.93 & 0.61 & $\mathrm{n} / \mathrm{a}$ \\
6 & 3.04 & 30.96 & $\mathrm{n} / \mathrm{a}$ \\
7 & 1.23 & 24.18 & $\mathrm{n} / \mathrm{a}$ \\
8 & 1.0 & 0.474 & 0.981 \\
9 & 3.1 & 0.416 & 0.984 \\
10 & 2.5 & 0.858 & 0.955 \\
11 & 3.44 & 147.4 & 0.945 \\
12 & 2.34 & 66.7 & 0.960 \\
13 & 3.14 & 41.7 & 0.978 \\
14 & 3.26 & 162.7 & 0.938
\end{tabular}

Table 3. Weibull modulus, $m$, and characteristic stress, $\sigma_{0}$, calculated herein by the MLE method $(2 P W)$. Inside the parentheses the standard deviation is given. 


\begin{tabular}{ccr}
\hline Number & $\begin{array}{c}\text { Weibull } \\
\text { modulus } m\end{array}$ & $\begin{array}{c}\text { Characteristic } \\
\text { stress } \sigma_{0} \\
{[\mathrm{MPa}]}\end{array}$ \\
\hline 1 & $1.44(0.21)$ & $\begin{array}{r}102.28(14.39) \\
2\end{array}$ \\
$1.65(0.23)$ & $38.98(4.55)$ \\
3 & $1.13(0.16)$ & $4.16(0.72)$ \\
4 & $1.96(0.31)$ & $0.69(0.07)$ \\
5 & $2.10(0.30)$ & $0.61(0.06)$ \\
6 & $2.36(0.17)$ & $32.32(1.44)$ \\
7 & $1.31(0.17)$ & $22.61(2.93)$ \\
8 & $1.06(0.16)$ & $0.47(0.09)$ \\
9 & $3.09(0.43)$ & $0.41(0.03)$ \\
10 & $2.49(0.36)$ & $0.86(0.07)$ \\
11 & $3.16(0.48)$ & $144.10(9.66)$ \\
12 & $2.05(0.31)$ & $64.45(6.80)$ \\
13 & $3.11(0.42)$ & $39.95(2.44)$ \\
14 & $2.92(0.32)$ & $140.06(7.58)$
\end{tabular}

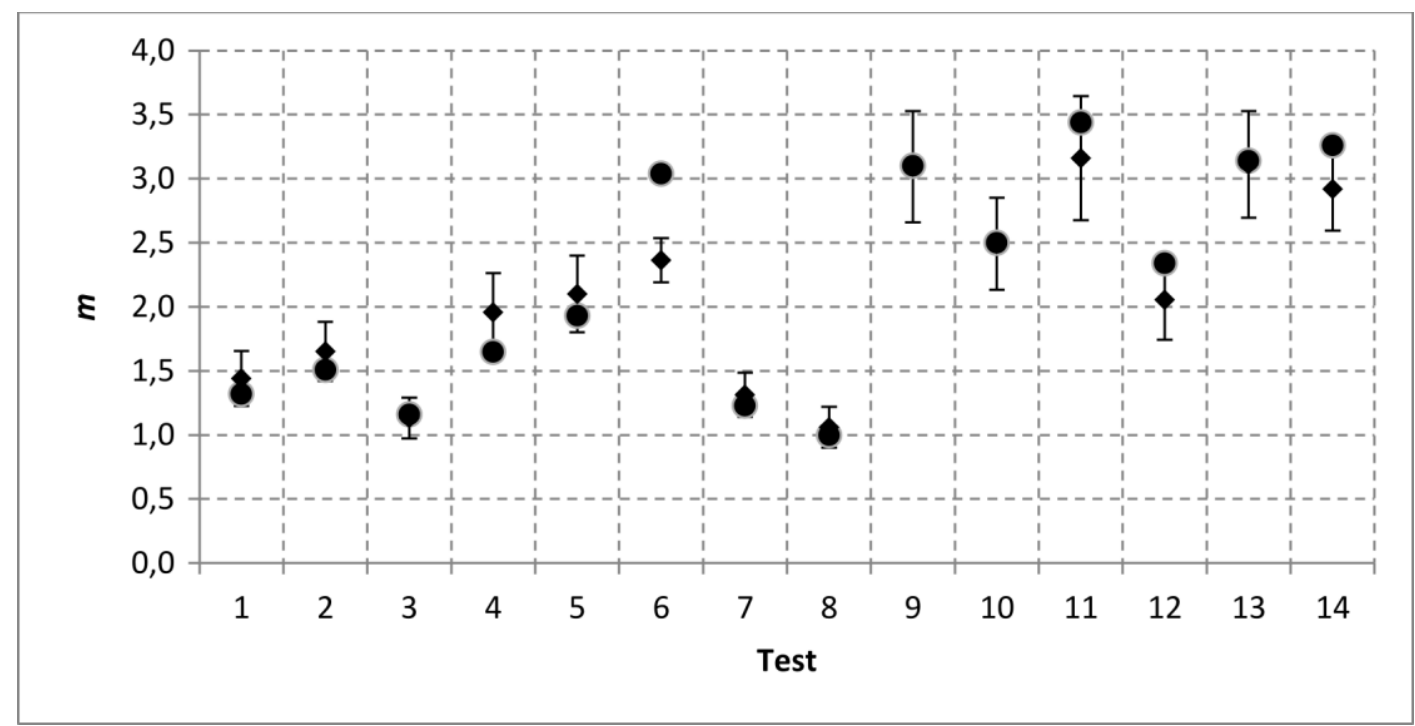

Figure 2. Comparison of the values of the Weibull modulus, $m$, for a two-parameter Weibull distribution that were determined in the present work (rhomboid markers) with the previously published values (circular markers). In almost all the cases the values found in the literature fall into the standard deviation margin. 


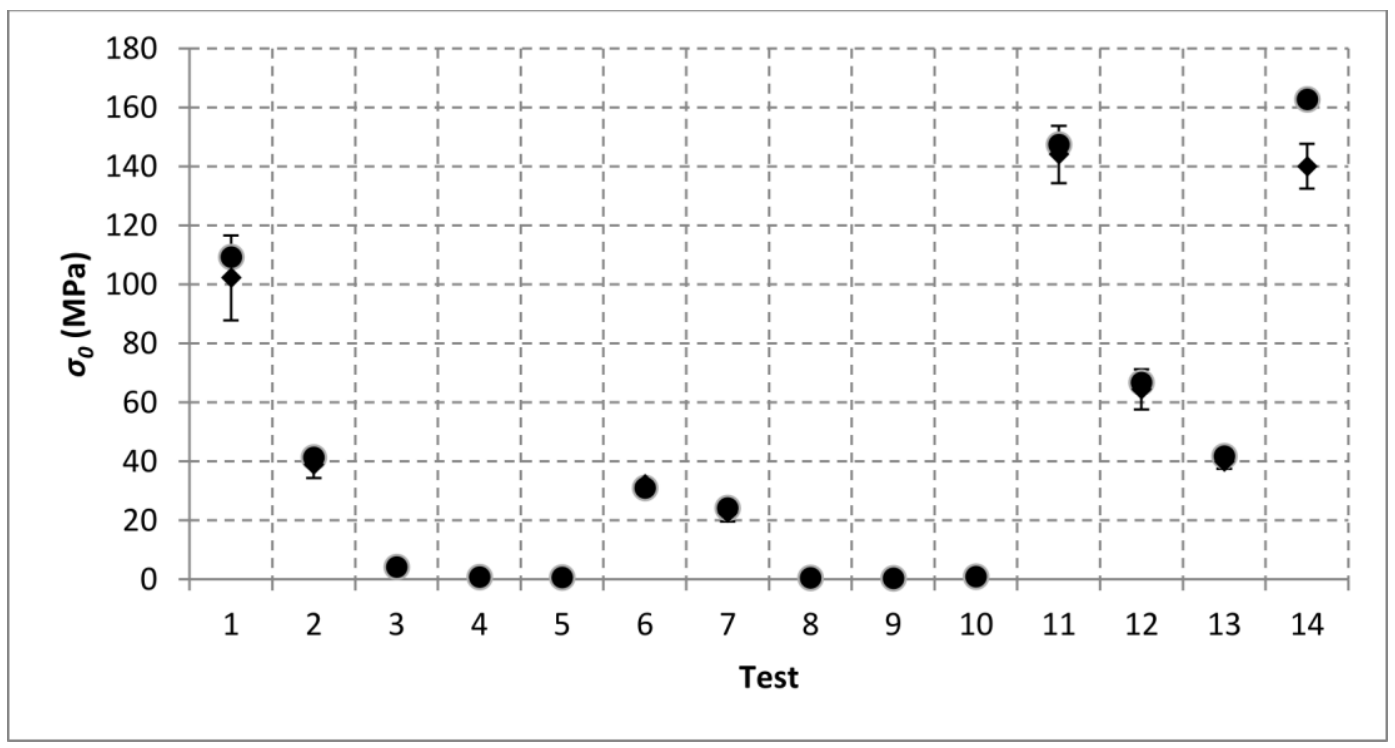

Figure 3. Comparison of the values of the characteristic stress, $\sigma_{0}$, for a two-parameter Weibull distribution that were determined herein (rhomboid markers) with the previously published values (circular markers). In most of the cases the values found in the literature fall into the standard deviation margin.

As it was mentioned in the previous paragraph a three-parameter Weibull distribution might better fit the experimental data due to the additional parameter, $\sigma^{*}$. This threshold was also used in the early papers of Weibull (e.g. Weibull, 1939a) in order to increase the accuracy of fitting. The failure stress threshold, $\sigma^{*}$, represents a critical stress under which grain failure is not possible (zero probability of failure). In other words it reflects a minimum stress (compression considered positive here) under which no infinitesimal sub-element of the grain can fail. In a log$\log$ plot the need of the additional parameter, $\sigma^{*}$, is demonstrated by the fact that the data points do not align on a straight line, but they bend for small stresses. The effect of $\sigma^{*}$ is to stretch the logarithmic axis of stresses offering this way a better fit. Figure 4 shows this behavior for No.14 data. A linear regression of the data is also presented showing the improvement of the coefficient of determination from 0.94 for $2 \mathrm{PW}$ to 0.99 for $3 \mathrm{PW}$. 

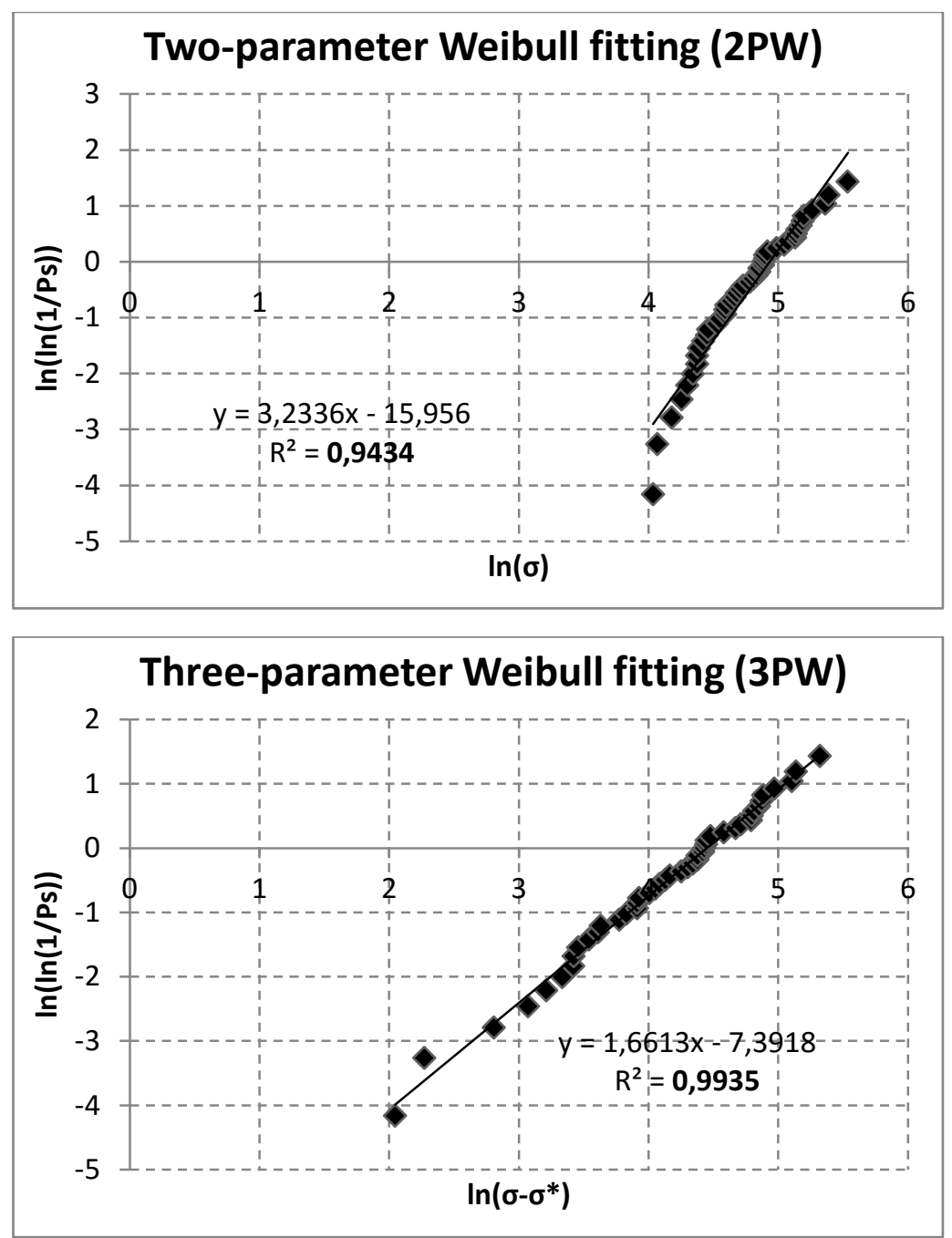

Figure 4. Two- and three-parameter Weibull fit of experimental data (No.14). The need of the additional parameter, $\sigma^{*}$, is demonstrated by the fact that the data points do not align on a straight line for $2 P W$, but they bend for small stresses. The effect of $\sigma^{*}$ is to stretch the logarithmic axis of stresses offering a better fit. A linear regression shows quantitatively this improvement.

In Table 4 we present the Weibull modulus, $m$, the characteristic stress, $\sigma_{0}$, and the threshold stress $\sigma^{*}$ for a three-parameter Weibull distribution, while in Table 5 the corresponding P-Values are given for a two- and three-parameter Weibull distribution. The three-parameter Weibull fitting improves considerably the calculated P-Value. Therefore, 3PW fitting seems to be more appropriate. However, in some cases 3PW made no difference and 2PW still describes the experimental data quite well. 
Table 4. Weibull modulus, $m$, characteristic stress, $\sigma_{0}$, and threshold stress $\sigma^{*}$ for a threeparameter Weibull distribution. Inside the parentheses the standard deviation of the parameters is given.

\begin{tabular}{|c|c|c|c|c|}
\hline Number & $\begin{array}{c}\text { Weibull } \\
\text { modulus } m\end{array}$ & $\begin{array}{c}\text { Characteristic } \\
\text { stress } \sigma_{0} \\
{[\mathrm{MPa}]}\end{array}$ & $\begin{array}{c}\text { Threshold } \\
\text { stress } \sigma^{*} \\
{[\mathrm{MPa}]}\end{array}$ & $\sigma^{*} / \sigma_{0}$ \\
\hline 1 & $1.44(0.21)$ & $102.28(14.39)$ & - & - \\
\hline 2 & $1.65(0.23)$ & $38.98(4.55)$ & - & - \\
\hline 3 & $0.90(0.13)$ & $3.31(0.72)$ & 0.47 & $14,1 \%$ \\
\hline 4 & $1.96(0.31)$ & $0.69(0.07)$ & - & - \\
\hline 5 & $1.88(0.27)$ & $0.55(0.06)$ & 0.05 & $8,5 \%$ \\
\hline 6 & $1.97(0.15)$ & $27.06(1.44)$ & 4.63 & $17,1 \%$ \\
\hline 7 & $1.31(0.17)$ & $22.61(2.93)$ & - & - \\
\hline 8 & $0.94(0.15)$ & $0.42(0.09)$ & 0.02 & $4,7 \%$ \\
\hline 9 & $2.19(0.32)$ & $0.30(0.03)$ & 0.10 & $35,0 \%$ \\
\hline 10 & $1.51(0.23)$ & $0.56(0.07)$ & 0.26 & $46,6 \%$ \\
\hline 11 & $1.47(0.24)$ & $72.79(10.40)$ & 62.71 & $86,2 \%$ \\
\hline 12 & $1.38(0.22)$ & $43.93(6.83)$ & 16.73 & $38,1 \%$ \\
\hline 13 & $2.25(0.31)$ & $29.09(2.46)$ & 10.01 & $34,4 \%$ \\
\hline 14 & $1.67(0.20)$ & $82.84(7.80)$ & 50.76 & $61,3 \%$ \\
\hline
\end{tabular}

Table 5. Calculated P-Values for a two- and three-parameter Weibull distribution.

\begin{tabular}{cccc}
\hline Name & $\begin{array}{c}\text { P-Value for } \\
\text { 3PW }\end{array}$ & $\begin{array}{c}\text { P-Value for } \\
\text { 2PW }\end{array}$ & $\Delta$ (P-Value) \\
\hline 1 & $97.01 \%$ & $97.01 \%$ & - \\
2 & $98.99 \%$ & $98.99 \%$ & - \\
3 & $91.20 \%$ & $58.05 \%$ & $33.15 \%$ \\
4 & $99.98 \%$ & $99.88 \%$ & $0.15 \%$ \\
5 & $100.00 \%$ & $100.00 \%$ & $0.00 \%$ \\
6 & $38.46 \%$ & $20.97 \%$ & $17.49 \%$ \\
7 & $100.00 \%$ & $100.00 \%$ & - \\
8 & $99.62 \%$ & $91.91 \%$ & $7.71 \%$ \\
9 & $100.00 \%$ & $99.98 \%$ & $0.02 \%$ \\
10 & $79.31 \%$ & $37.68 \%$ & $41.63 \%$ \\
11 & $100.00 \%$ & $98.79 \%$ & $1.21 \%$ \\
12 & $99.89 \%$ & $90.87 \%$ & $9.02 \%$ \\
13 & $92.91 \%$ & $74.77 \%$ & $18.14 \%$ \\
14 & $99.97 \%$ & $83.24 \%$ & $16.73 \%$
\end{tabular}




\section{Rock sugar tests}

A series of single grain crush tests on rock sugar grains (RS) was performed (Figure 5). The tests were performed using a 50kN TriScan VJTech load frame (Figure 5). The apparatus is displacement controlled and applies constant vertical displacement rates. The applied force was measured using a 500daN FGP Instrumentation load cell and the displacements through a Mitoyo 543-690B LVDT with $0-12.7 \mathrm{~mm}$ measuring range and $0.001 \mathrm{~mm}$ resolution. The data acquisition rate was $1 \mathrm{~Hz}$. The sugar grains are placed between two flat glass platens in order to reduce friction. All the tests were performed under the same conditions, i.e. humidity, temperature and applied strain rate $(1 \mathrm{~mm} / \mathrm{min})$. The particles showed brittle failure, breaking in several distinct pieces each time.
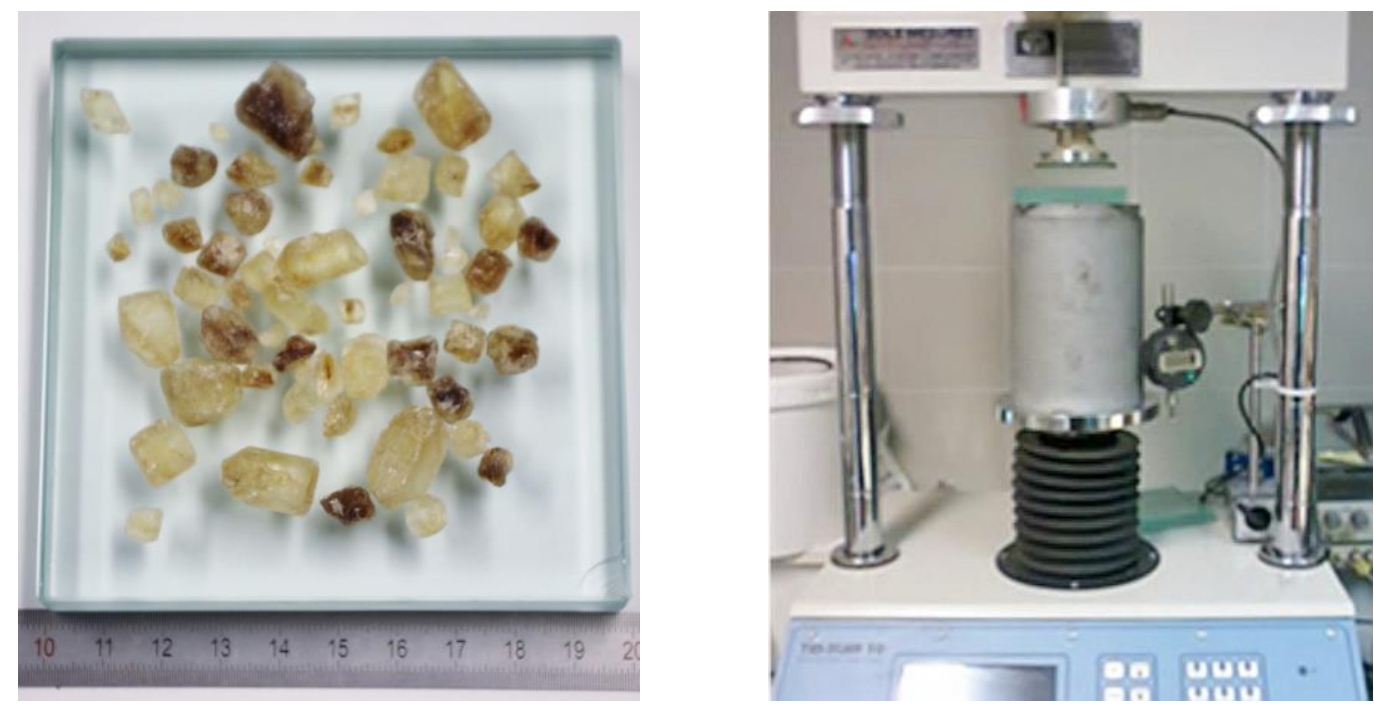

Figure 5. Left: Rock sugar grains (particles) of various sizes. Right: Single-grain crush test apparatus.

In Figure 6 we present a typical force-deformation curve of a sugar grain crush test. It should be mentioned that the definition of the force required to crush a particle is not straightforward due to the gradual breakage of the grain's asperities before the maximum load force is attained (Nakata, Kato, et al., 2001). This is depicted in Figure 6, where a first peak in force is observed before the maximum load. In the present paper the maximum force was considered as a measure for the 
force required for grain crushing, $F_{f}$. In most of the cases this force corresponds to the point at which the grain splits into several smaller ones.

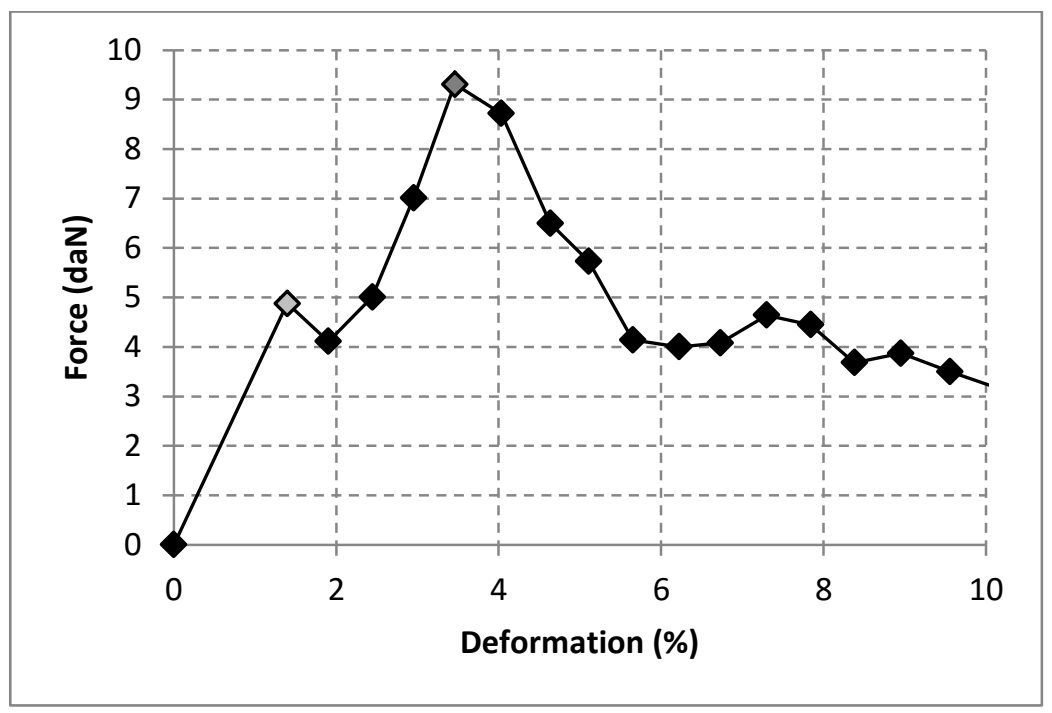

Figure 6. Typical force-deformation curve of a sugar grain in compression.

Due to the crystal structure of sucrose, which is monoclinic, the final shape of the rock sugar crystals is not irregular, but it has a certain geometrical order. Nevertheless, because of the random packing of the sucrose crystals during the formation of the large rock sugar crystals, the final shape and the size of the particles tested show an important variability. Consequently, the definition of a failure stress is not straightforward. In the present study an effective grain diameter was determined for each grain by calculating the volume of each particle through its weight. The density is considered constant and the particles are assumed to be similar in shape. The failure stress is proportional to the failure force and inversely proportional to the square of the effective diameter of the grains:

$$
\sigma_{f}=\frac{F_{f}}{\alpha d_{e f f}^{2}}
$$

where $d_{\text {eff }}$ is the effective grain diameter and $\alpha$ a shape parameter which was considered equal to one herein for simplicity. In any case, contrary to deterministic approaches (e.g. Russell \& Muir Wood, 2009), the shape of the particles, as well as other factors such as the roughness of their surface or their size, is described stochastically through the parameters of the Weibull distribution. 
Four testing groups were distinguished based on grain size. The particles were sieved using sieves of $3 \mathrm{~mm}, 5 \mathrm{~mm}, 6.3 \mathrm{~mm}, 8 \mathrm{~mm}$ and $10 \mathrm{~mm}$. In Table 6 we summarize the four testing groups and the number of particles tested for each group. In Table 7 and Table 8 we present respectively the Weibull parameters for a two- and a three-parameter Weibull distribution fitting of the failure stress of the sugar particles. Finally, in Table 9 the corresponding P-Values are given for the distributions. The three-parameter Weibull fitting shows again a higher P-Value and consequently it seems to describe better the ultimate failure stress of the sugar particles. The threshold stress is on average $20 \%$ of the characteristic stress and it decreases with increasing diameter. Figure 7 and Figure 8 show a comparison of the fitted cumulative distribution functions with a two- and three-Weibull distribution functions for RS $5.0-6.3 \mathrm{~mm}$ and RS $6.3-8.0 \mathrm{~mm}$, respectively. Notice that with $3 \mathrm{PW}$ the probability of failure below the calculated threshold stress, $\sigma^{*}$, is zero.

Table 6. Rock sugar grain tests.

\begin{tabular}{lc}
\hline \multicolumn{1}{c}{ Group name } & $\begin{array}{c}\text { Number of } \\
\text { particles tested }\end{array}$ \\
\hline RS 3.0-5.0mm & 45 \\
RS 5.0-6.3mm & 48 \\
RS 6.3-8.0mm & 39 \\
RS $8.0-10.0 \mathrm{~mm}$ & 41
\end{tabular}

Table 7. Fitting of the failure stress of rock sugar grains with a two-parameter Weibull distribution. Inside the parentheses the standard deviation is given.

\begin{tabular}{lcc}
\hline \multicolumn{1}{c}{ Group name } & $\begin{array}{c}\text { Weibull } \\
\text { modulus } m\end{array}$ & $\begin{array}{c}\text { Characteristic } \\
\text { stress } \sigma_{0} \\
{[\mathrm{MPa}]}\end{array}$ \\
\hline RS 3.0-5.0mm & $1.98(0.21)$ & $3.76(0.30)$ \\
RS 5.0-6.3mm & $2.21(0.24)$ & $3.48(0.24)$ \\
RS 6.3-8.0mm & $1.98(0.22)$ & $2.59(0.22)$ \\
RS 8.0-10.0mm & $2.07(0.24)$ & $1.99(0.16)$
\end{tabular}

Table 8. Fitting of the failure stress of rock sugar grains with a three-parameter Weibull distribution. Inside the parentheses the standard deviation is given.

\begin{tabular}{ccccc}
\hline Group name & Weibull & Characteristic & Threshold & $\sigma^{*} / \sigma_{0}$ \\
\hline
\end{tabular}




\begin{tabular}{lcccc}
\hline & modulus $m$ & $\begin{array}{c}\text { stress } \sigma_{0} \\
{[\mathrm{MPa}]}\end{array}$ & $\begin{array}{c}\text { stress } \sigma^{*} \\
{[\mathrm{MPa}]}\end{array}$ & \\
\hline RS 3.0-5.0mm & $1.58(0.17)$ & $2.95(0.30)$ & 0.67 & $22.8 \%$ \\
RS 5.0-6.3mm & $1.72(0.19)$ & $2.76(0.24)$ & 0.61 & $22.2 \%$ \\
RS 6.3-8.0mm & $1.50(0.18)$ & $1.92(0.22)$ & 0.56 & $29.2 \%$ \\
RS 8.0-10.0mm & $1.81(0.22)$ & $1.76(0.16)$ & 0.20 & $11.4 \%$
\end{tabular}

Table 9. Calculated P-Values for a two- and three-parameter Weibull distribution.

\begin{tabular}{lccc}
\hline \multicolumn{1}{c}{ Group name } & $\begin{array}{c}\text { P-Value for } \\
\text { 3PW }\end{array}$ & $\begin{array}{c}\text { P-Value for } \\
\text { 2PW }\end{array}$ & $\Delta$ (P-Value) \\
\hline RS 3.0-5.0mm & $85.64 \%$ & $67.70 \%$ & $17.94 \%$ \\
RS 5.0-6.3mm & $99.99 \%$ & $99.99 \%$ & $0.00 \%$ \\
RS 6.3-8.0mm & $76.47 \%$ & $44.95 \%$ & $31.52 \%$ \\
RS 8.0-10.0mm & $85.59 \%$ & $78.68 \%$ & $6.91 \%$
\end{tabular}

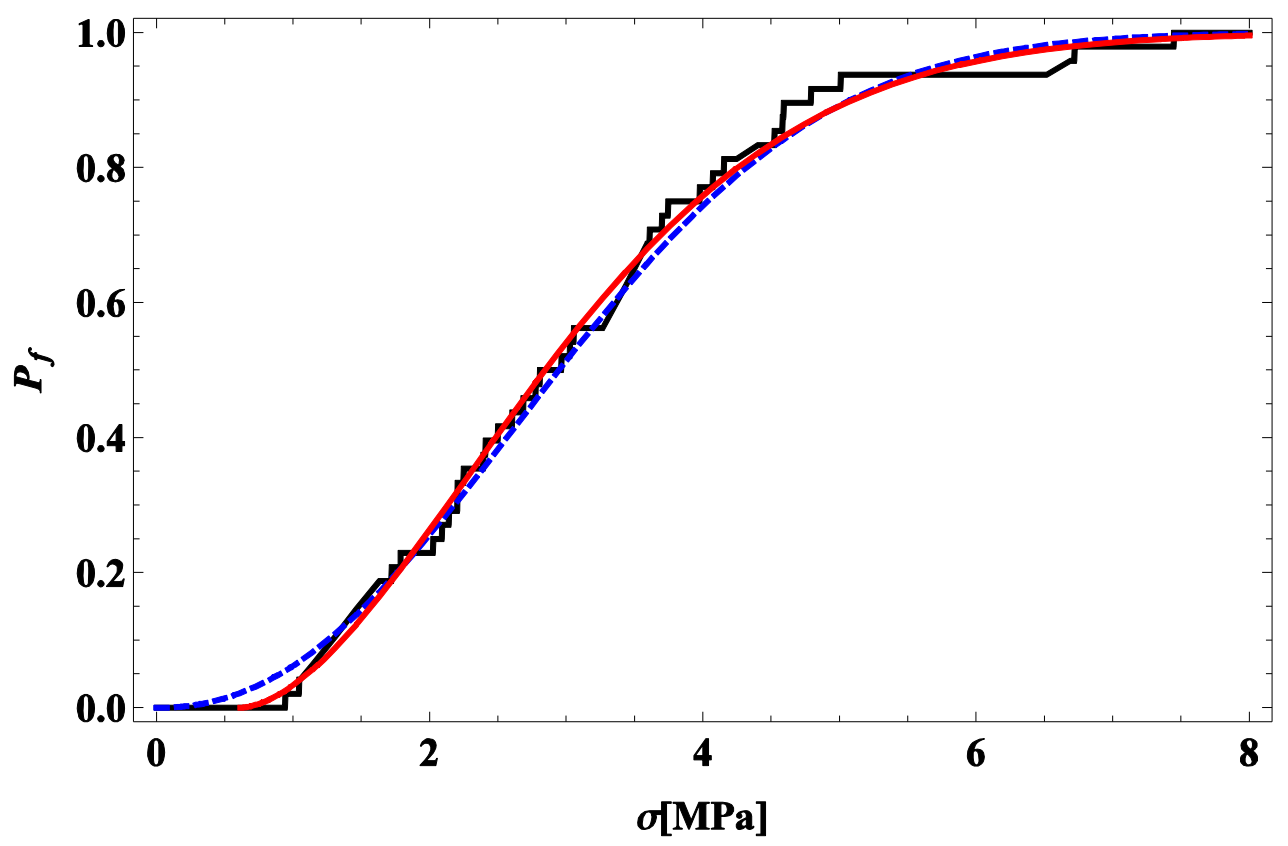

Figure 7. Cumulative distribution function for 5.0-6.3mm rock sugar particles (solid black line) and their 3PW (solid red line) and 2PW (dashed blue line) fittings. 


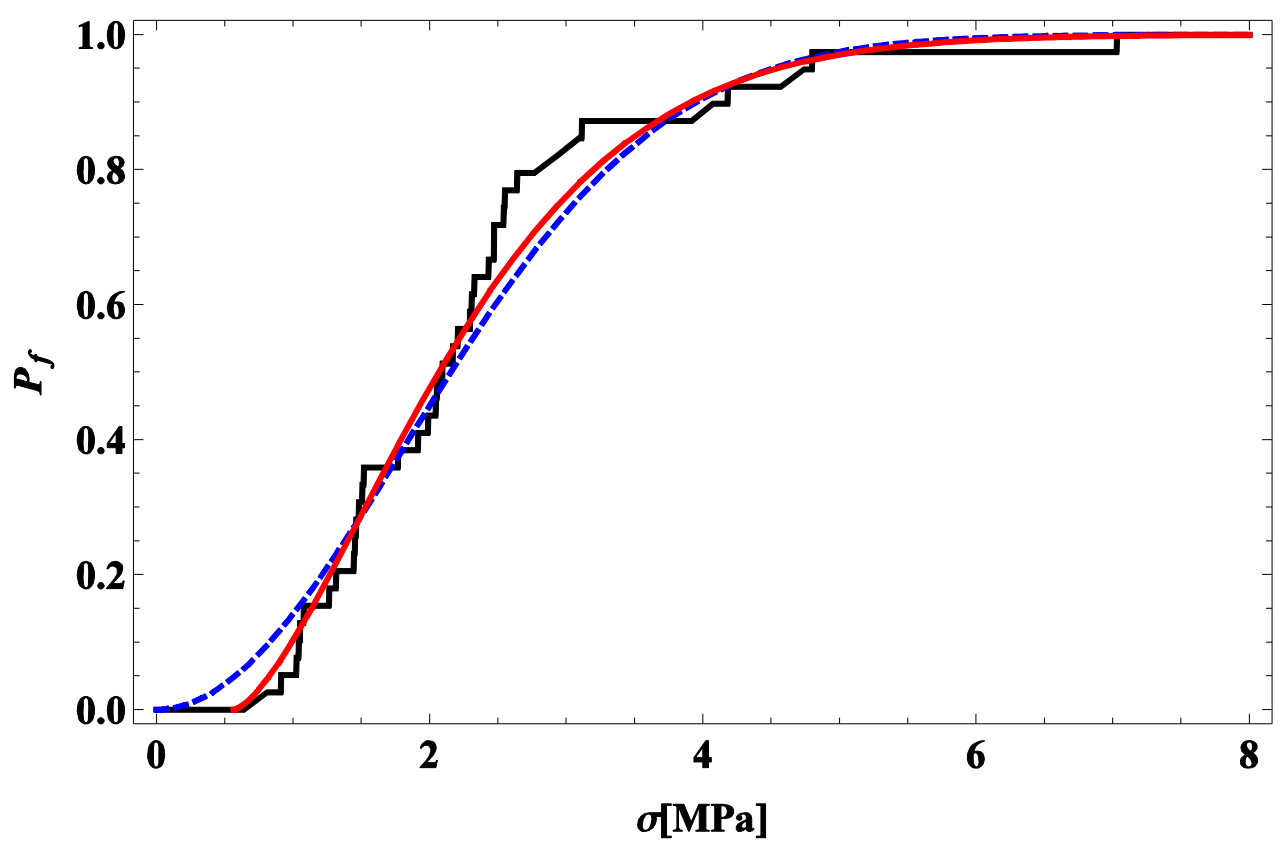

Figure 8. Cumulative distribution function for 6.3-8.0mm rock sugar particles (solid black line) and their 3PW (solid red line) and $2 P W$ (dashed blue line) fittings.

\section{Grain size effect}

The strength of a grain depends on many factors such as its material properties, its shape (e.g. roundness), its size, its roughness, the presence of flaws in the bulk etc.. These are important factors that are captured in a stochastic manner through the Weibull distribution. In geomechanics and in geotechnics, the evolution of strength with grain size plays significant role. The effect of the particle size on the strength of a uniform granular assembly can be experimentally quantified by performing tests with different grain sizes. However, performing grain crushing tests with particles of identical size and shape is not possible with natural particles, such as the particles studied herein, due to their size variability. As shown in Table 1 and Table 6 a narrow range of particles size is selected after sieving. The size range should be relatively small in order to assure the existence of only one population for each series of particle tests. Otherwise, a multi-modal statistical distribution would be needed. As far it concerns the experimental results at hand, no strong evidence was found on the coexistence of two (or more) different populations in the same grain size range/test. 
The particle size, as well as the other factors that were mentioned above, is embedded into the parameters of the Weibull distribution. In other words, the characteristic stress takes different values for different ranges of particle sizes. This is a well-known aspect which has been studied extensively in the past for the 2PW distribution (see for instance Nakata, Kato, et al., 2001). In particular, it was shown that the characteristic stress decreases with increasing particle size. This tendency is also reported for the 3PW. In Figure 9 and Figure 10 we present the dependency of the characteristic and threshold stresses on the particles' size using the tests of McDowell (2002) and the tests performed herein on rock sugar particles, respectively. The available data in the literature were not enough for exploring the dependence of the Weibull parameters on the grain size for all the tests presented in Table 1. McDowell \& Amon (2000) results could also be included for studying the particle size effect, but, as it shown in Table 4, the 3PW fit coincides with the $2 \mathrm{PW}$ in most of the cases for these tests (zero threshold stress). This might be because of the nature of the grains or due to the small number of the particles tested for each nominal diameter.

A decreasing monotonic tendency is observed for increasing particles' size for both the characteristic and threshold stresses. For the characteristic stress, $\sigma_{0}$, (Weibull's scale parameter) a linear trend in the log-log space is noticed with a relatively good coefficient of determination, both for the McDowell (2002) tests and the rock sugar tests performed herein. This is almost the case for the threshold stress, $\sigma^{*}$, (Weibull's shift parameter) except the last point in Figure 10, which corresponds to the RS $8.0-10.0 \mathrm{~mm}$ tests. This might be attributed to the change of the geometry of the bigger particles (Figure 5), which becomes less similar in shape than the particles of smaller sizes. In any case, smaller particles show a higher threshold stress, which is an aspect that might be important for micromechanical models involving small particles.

It is worth noticing that for the 3PW distribution the characteristic stress does not scale with $d_{e f f}^{-3 / m}$ , scaling discussed in McDowell \& Bolton (1998). This means that the "material function" (the function in the exponent of the distribution, see Weibull, 1939a) is not proportional to the volume of the grain. According to Weibull, this is explained by considering that the internal stress fields inside the particle are non-uniform, which is the case for the geometry and the type of the tests performed. The above scaling is not applicable even for the $2 \mathrm{PW}$ fitting for the rock sugar tests. Assuming a scaling of the form $d_{\text {eff }}^{-\beta / m}$ for the characteristic stress, it is found that $\beta \approx 1.2$ scales 
quite well both McDowell (2002) and the rock sugar data for the 3PW. A scaling of similar form was also adopted by Mogi (1962) for the fracture strength of rock specimens, which are influenced not only by their volume, but also by the cross-sectional area of the specimens.
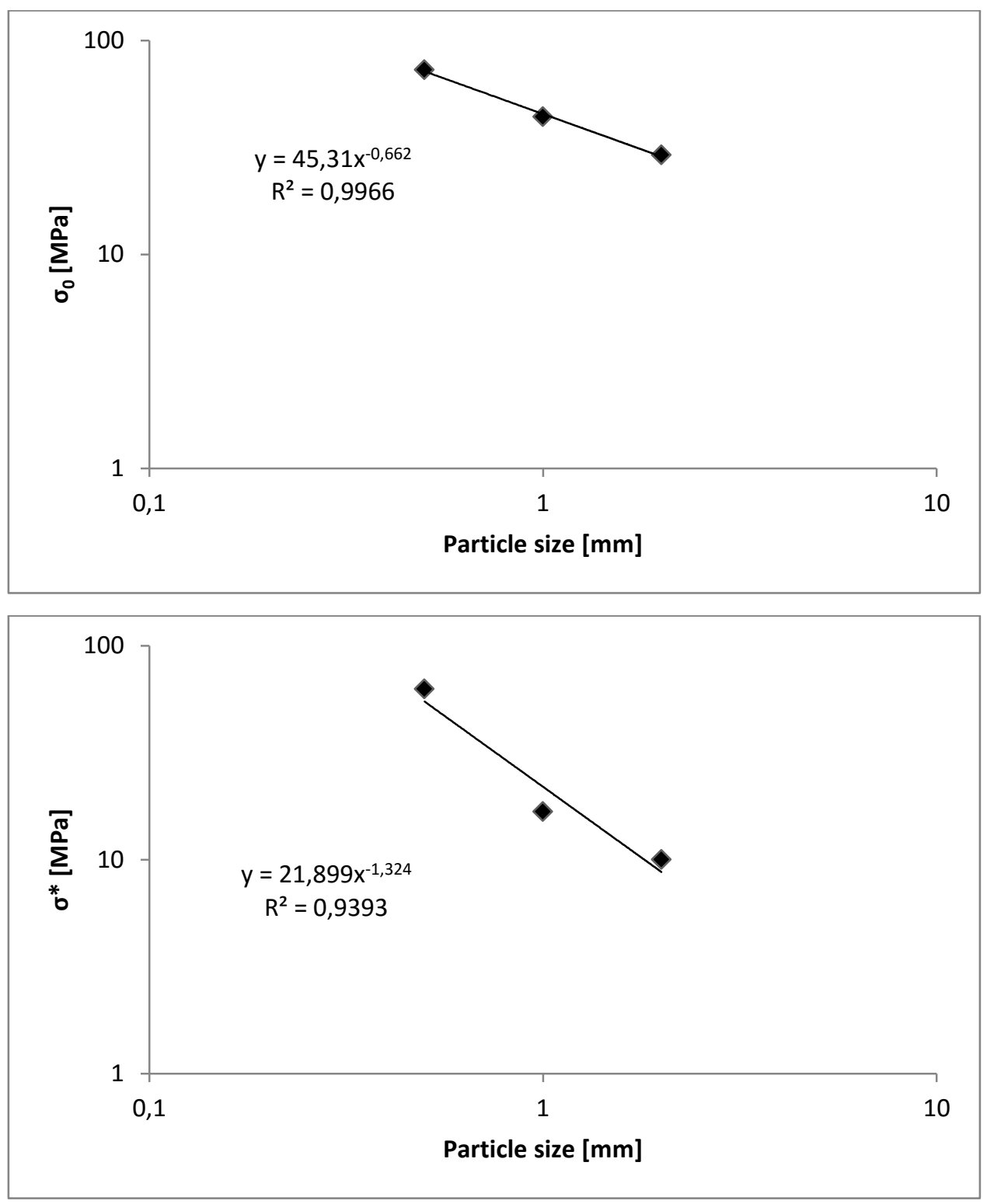

Figure 9. Dependence of the characteristic stress, $\sigma_{0}$, and of the threshold stress, $\sigma^{*}$, on the particle size. Mcdowell (2002) tests. 

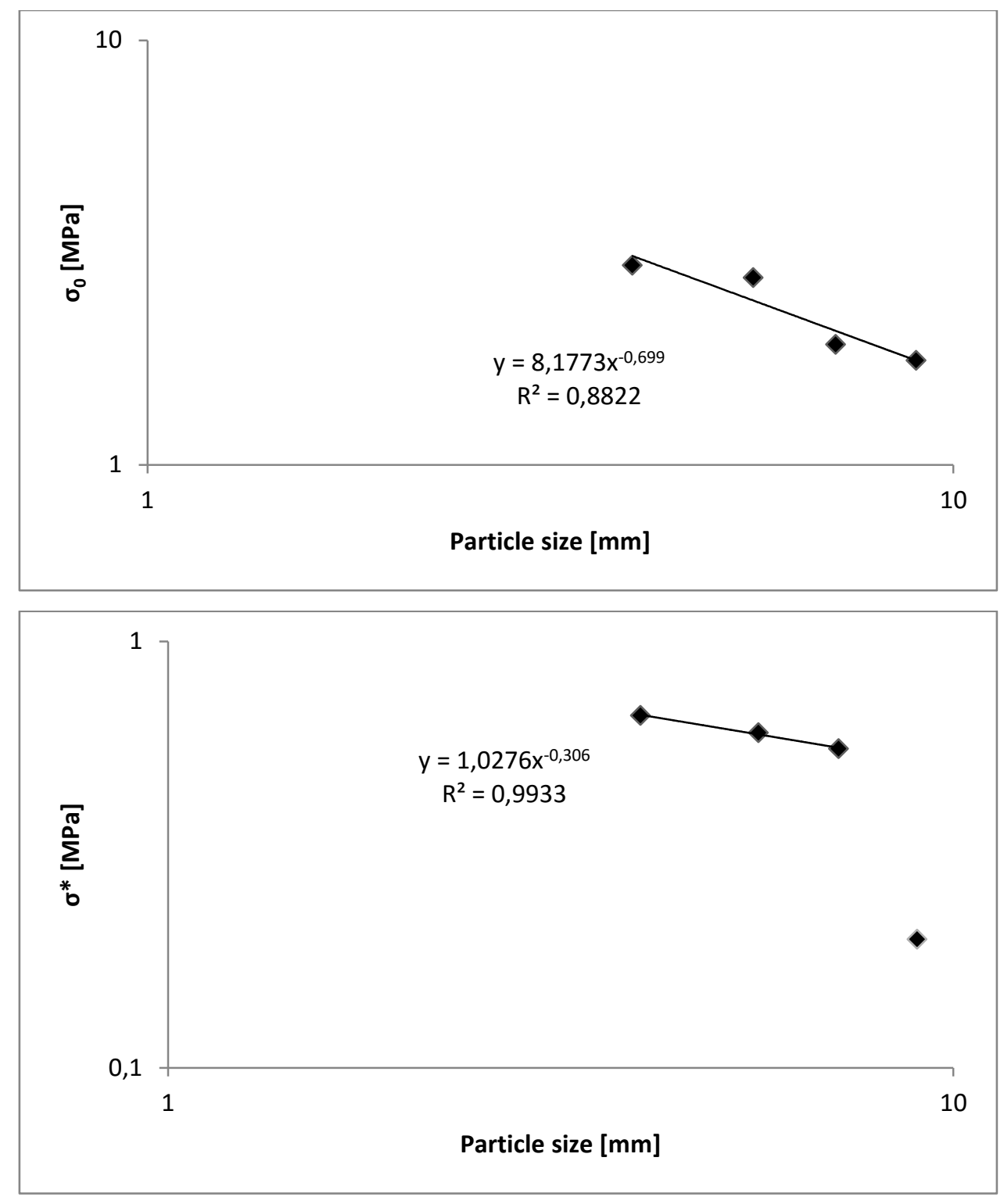

Figure 10. Dependence of the characteristic stress, $\sigma_{0}$, on the particle size for the rock sugar particles.

\section{Conclusions}

Grain crushing plays an important role in the mechanical behavior of granular media. The resistance to breakage of single grains might be related to several phenomena in various disciplines and engineering. For instance, the size of strain localization bands is a function of the average grain size. Grain crushing might also trigger instabilities and might be related to creep 
and other chemo-thermo-poro-mechanical processes. The probability of failure of single grain particles is frequently described by a two-parameter Weibull distribution, which predicts that failure is possible at any stress level. Nevertheless, even in the early works of Weibull a threeparameter Weibull distribution was used as it provided a better fit (Weibull, 1939a, 1939b, 1951). In the current paper, several existing experimental data that concern the resistance of individual brittle grains were re-processed in order to investigate whether a two- or rather a three-Weibull distribution describes adequately the probability of failure of a single grain. The existing experimental data involved sand particles of different origin, chemical composition and geometry as well as grains from surrogate materials such as pasta, rice and cornflakes. This data were completed with a series of grain crushing tests on rock sugar particles, which are large crystals of sucrose. The post-processing of the results showed that in general a three-parameter Weibull distribution can better describe the probability of failure of single grains. This means that there is a stress threshold under which grain crushing is not likely to happen at all.

The parameters of the distribution depend on the particle size. A decreasing monotonic tendency was observed for increasing particles' size for both the characteristic and threshold stresses. In other words, the smaller particles show a higher threshold stress, i.e. they are stronger and uncrushable for small stresses (zero probability of failure). This is an aspect that can be important for micromechanical models. Finally, it was found that for the 3PW distribution and for the data processed herein, the characteristic stress does not scale with $d_{e f f}^{-3 / m}$, scaling used in McDowell \& Bolton (1998). This means that the "material function" (the function in the exponent of the distribution, see Weibull, 1939a) is not only proportional to the volume of the grain, but also to their cross-sectional area, for instance. This could be explained by the fact that the internal stress field in the grains is not uniform. A more general scaling, of the form $d_{\text {eff }}^{-\beta / m}$, which is similar to the one used by Mogi (1962) for the fracture strength of rock specimens, seemed to better scale McDowell (2002) and the rock sugar tests for the 3PW distribution.

It is worth mentioning that other distributions might be used as well and in some cases they might show an improved goodness of fit. Nevertheless, the Weibull distribution ansatz for grain crushing has a clear physical meaning as it is justified by the extreme value theorem in statistics and the weakest link concept. Moreover, the use of this distribution is corroborated by experiments of individual grain crushing for different geomaterials. 


\section{References}

Alshibli, K. A., \& Cil, M. B. (2012). 3D assessment of fracture of sand particles using discrete element method. Géotechnique Letters, 2(July-September), 161-166. doi:10.1680/geolett.12.00024

Brantut, N., \& Sulem, J. (2012). Strain Localization and Slip Instability in a Strain-Rate Hardening, Chemically Weakening Material. Journal of Applied Mechanics, 79(3), 031004. doi: $10.1115 / 1.4005880$

de Haan, L., \& Ferreira, A. (2006). Extreme Value Theory: An Introduction. Springer. Retrieved from http://www.tandfonline.com/doi/abs/10.1198/jasa.2008.s231

Einav, I. (2007). Breakage mechanics-Part I: Theory. Journal of the Mechanics and Physics of Solids, 55(6), 1274-1297. doi:10.1016/j.jmps.2006.11.003

Hidalgo, R., Grosse, C., Kun, F., Reinhardt, H., \& Herrmann, H. J. (2002). Evolution of Percolating Force Chains in Compressed Granular Media. Physical Review Letters, 89(20), 205501. doi:10.1103/PhysRevLett.89.205501

Lade, P. V., Yamamuro, J. A., \& Bopp, P. A. (1996). Significance of Particle Crushing in Granular Materials. Journal of Geotechnical Engineering, 122(4), 309-316. doi:10.1061/(ASCE)0733-9410(1996)122:4(309)

Mcdowell, G. R. (2002). On the yielding and plastic compression of sand. Soils and Foundations, 42(1), 139-145. Retrieved from http://cat.inist.fr/?aModele=afficheN\&cpsidt=14156427

McDowell, G. R., \& Amon, A. (2000). The application of Weibull statistics to the fracture of soil particles. Soils and Foundations, 40(5), 133-141.

McDowell, G. R., \& Bolton, M. D. (1998). On the micromechanics of crushable aggregates. Géotechnique, 48(5), 667-679. doi:10.1680/geot.1998.48.5.667

Mcdowell, G. R., Cil, M. B., Li, H., \& Alshibli, K. A. (2013). Discussion: 3D assessment of fracture of sand particles using discrete element method. Géotechnique Letters, 3(JanuaryMarch), 13-15. doi:10.1680/geolett.13.00004

McDowell, G. R., \& Humphreys, A. (2002). Yielding of granular materials. Granular Matter, 4, 1-8. doi:10.1007/s10035-001-0100-4

Mogi, K. (1962). The influence of the dimensions of specimens on the fracture strength of rocks. Bulletin of the Earthquake Research Institute, 40, 175-185.

Mühlhaus, H. B., \& Vardoulakis, I. (1987). The thickness of shear bands in granular materials. Géotechnique, 37(3), 271-283. doi:10.1680/geot.1987.37.3.271

Nakata, Y., Hyde, A. F. L., Hyodo, M., \& Murata, H. (1999). A probabilistic approach to sand particle crushing in the triaxial test. Géotechnique, 49(5), 567-583.

Nakata, Y., Hyodo, M., Hyde, A. F. L., Kato, Y., \& Murata, H. (2001). Microscopic particle crushing of sand subjected to high pressure one-dimensional compression. Soils and 
Foundations, 41(1), 69-82.

Nakata, Y., Kato, Y., Hyodo, M., Hyde, A. F. L., \& Murata, H. (2001). One-dimensional compression behaviour of uniformly graded sand related to single particle crushing strength. Soils and Foundations, 41(2), 39-51. Retrieved from http://cat.inist.fr/?aModele=afficheN\&cpsidt=1002257

Regenauer-lieb, K., Veveakis, E., Poulet, T., Wellmann, F., Karrech, A., Liu, J., ... Trefry, M. (2013). Multiscale coupling and multiphysics approaches in earth sciences: Theory. Journal of Coupled Systems and Multiscale Dynamics, 1(1), 49-73. doi:10.1166/jcsmd.2013.1012

ReliaSoft Corporation. (2013). Discussion of Maximum Likelihood Estimation for the 3Parameter Weibull Distribution. Retrieved from http://www.weibull.com/hotwire/issue148/hottopics148.htm

ReliaSoft Corporation. (2014). Weibull++: Life Data Analysis (Weibull Analysis) Software Tool.

Rinne, H. (2009). The Weibull Distribution: A handbook. Giessen, Germany: CRC Press. Retrieved from http://reliawiki.org/index.php/The_Weibull_Distribution

Russell, A. R., \& Muir Wood, D. (2009). Point load tests and strength measurements for brittle spheres. International Journal of Rock Mechanics and Mining Sciences, 46(2), 272-280. doi:10.1016/j.ijrmms.2008.04.004

Stefanou, I., \& Sulem, J. (2014). Chemically induced compaction bands: Triggering conditions and band thickness. Journal of Geophysical Research: Solid Earth, 119(2), 880-899. doi:10.1002/2013JB010342

Sulem, J., \& Famin, V. (2009). Thermal decomposition of carbonates in fault zones: Slipweakening and temperature-limiting effects. Journal of Geophysical Research, 114(B3), B03309. doi:10.1029/2008JB006004

Sulem, J., Stefanou, I., \& Veveakis, E. (2011). Stability analysis of undrained adiabatic shearing of a rock layer with Cosserat microstructure. Granular Matter, 13(3), 261-268. doi:10.1007/s10035-010-0244-1

Vardoulakis, I., \& Sulem, J. (1995). Bifurcation Analysis in Geomechanics. Library. Glascow: Blackie.

Veveakis, E., Stefanou, I., \& Sulem, J. (2013). Failure in shear bands for granular materials: thermo-hydro-chemo-mechanical effects. Géotechnique Letters, 3(April-June), 31-36. doi:10.1680/geolett.12.00063

Veveakis, E., Sulem, J., \& Stefanou, I. (2012). Modeling of fault gouges with Cosserat Continuum Mechanics: Influence of thermal pressurization and chemical decomposition as coseismic weakening mechanisms. Journal of Structural Geology, 38, 254-264. doi:10.1016/j.jsg.2011.09.012

Weibull, W. (1939a). A statistical theory of the strength of materials. Royal Swedish Institute for Engineering Research.

Weibull, W. (1939b). The Phenomenon of Rupture in Solids. Proceedings of Royal Swedish Institute of Engineering Research. 
Weibull, W. (1951). A Statistical Distribution Function of Wide Applicability. Journal of Applied Mechanics. 